\title{
Analysis of work-life balance from the viewpoint of Iranian accountants
}

\author{
Abbas Ghanbari ${ }^{\mathrm{a}}$, Morteza Ramazani ${ }^{\mathrm{b}^{*}}$ and Majid Jalilinia ${ }^{\mathrm{c}}$
}

${ }^{a}$ Management Department, Hidaj Branh, Islamic Azad University, Hidaj, Iran

${ }^{b}$ Young Researchers and Elite Club, Zanjan Branch, Islamic Azad University, Zanjan, Iran

${ }^{c}$ Management Department, Shahid Beheshti University. Tehran, Iran

\section{CHR O I C L E A B S T R A T}

Article history:

Received May 1, 2013

Received in revised format 10 July 2013

Accepted 12 July 2013

Available online

July 142013

Keywords:

Work-life balance

$W L B$

Accounting Profession

\begin{abstract}
Work-life balance (WLB) plays an essential role on having peaceful life. There has been a substantial growth of families where both husband and wife work. Despite enjoying advantages of role mixture, life style in family has been faced by tremendous pressures due to ignoring conventional division of work in family as well as making new and more commitments. One of these pressures is the conflict between work and life, which could lead to unfavorable impacts on social integrity of family functions, mental and social health. This paper investigates WLB in terms of accountants' perspective. The proposed study designs a questionnaire, which contains 12 questions where 6 questions are associated with the importance of WLB and the other 6 questions are associated with effective variables in creating WLB. The method of the research is descriptive-survey and the study uses ANOVA test to analyze the results. The researcher has employed Friedman test to score research variables. The results of the research indicate that WLB components had different rates of importance among accountants with various genders.
\end{abstract}

\section{Introduction}

Experts in the area of humanities have always paid considerable attention to family as the most primary and important social entity. The status of family as a primary social entity has always posed questions. What gives considerable consequence to discussion around family is its direct influence on secondary social entities (Paknahad, 2000). According to circumstantial evidence in Iran's annals, whether classic or temporary, social transformations have always been based on family owing to the fact that Iran's social framework with focus on orderly family and its changes has direct impact on the whole social life (Azad Armaki, 2007). 
It goes without saying that family is a historical phenomenon; that is it was first formed at a certain period in social transformations and that it has undergone tremendous changes. Thus, the emergence of family in history has been synchronized with division of labor in society based on age and gender and this fact has occasioned emergence of nomadic tribes (Taghva, 2000). We all know that human being is a social creature or according to Aristotle "political animal" who settles down to work today in the face of environmental diversity and pace of change in technological advancement and change in social framework and economic status. In fact, working is the common ground and precondition in human life (Tavassoli, 2008). In other words, the life of human being in society is limited to working. For hundreds of years, human being has subjugated nature by exercising his knowledge and sagacity to make tools (Tavassoli, 2008).

The phenomenon of role conflict generally and the conflict between occupational roles specifically is totally undeniable both in ongoing and emerging societies. Thus it is probable that people in both families, other than playing their roles both in family and job, are stuck in a situation in which they find out they cannot fulfill their parts satisfactorily in both or one of the roles entrusted to them and that one role hampers the progress of the other role. Therefore, the role conflict in a situation like this can, on the one hand, create stress and put mental well-being of the individual at hazard and, on the other hand, undermine his relationship with others both in family and on the job and consequently prevent the individual from playing his role satisfactorily in both roles (Rastghar Khaled, 2006).

Regarding the fact that striking balance between job and life is challenging for jobholders, the researcher embarks on investigating the importance of peoples' status (accountants) on work-life balance and variables involved in striking that balance from the viewpoint of accountants and investigating whether differences in gender are related to work-life balance.

In this research, we try to demonstrate conditions and grounds that guarantee balance between job and life in the area of accounting and present some guidelines in this respect. Objective of this study is analysis of work-life balance from the viewpoint of accountants in selecting jobs and influential variables in striking balance between job and life.

\section{Literature Review}

In the beginning of the third millennium in the era of globalization, human societies move towards a knowledge-driven society in the sense that boosting knowledge is the mainstay of progress in today's societies. Development of human resources in order to attain the goals of social and economic development is of paramount importance (Tavassoli, 2008). The course of history suggests that human being has never had enough of what he already possessed. Instead, he has always been trying to obtain what he needed and did not have access to. Thus, his relationships get more and more complicated and take on the impression of culture. On the other hand, social life requires cooperation, coordination and fulfillment of reciprocal needs. This fact has led to division of labor, enhancement of different skills and added more to qualitative and quantitative progress and their upshots and it has boosted human being's systematic relations in the form of institutes and organizations (Tavassoli, 2008).

Family in modern times has lost most of its previous functions and has taken on limited ones (Azad Armaki, 2007). Today job and family are two important social entities for both individual and society. These two entities have an influential role in establishing order and stability in both individual and society. A society in which the possibility of enhancing the system of social roles for each individual is high and Social framework requirements and interests in individual progress demand having the privileges of role build-up is undeniable. (Rastghar Khaled, 2006). The process of social development has caused radical changes in some societies such as Iran. The radical nature, quick and imbalanced process of these changes has created various social issues and threats for societies, which are related to conflicting norms and have caused disorder in social order along with 
other symbolic, relative and distributive disorders. In such a situation the assistant actor is entangled involuntarily and independently in a condition in which it is required to play several social roles by itself; roles that require uncoordinated behavior. Occurrence of role conflict in job and family roles, which is part of the main roles of an individual in his life, culminates in social unfavorable results that can jeopardize social order at different levels. (Rastghar Khaled, 2006). Note that reduction in job and family satisfaction are two separate upshots of family and job conflicts, which would consequently have a negative effect on an individual's satisfaction in lifestyles, contend that conflicts between jobfamily roles. It can indicate existence of tension in peoples' life, which would consequently bring about marital life incompatibility, insufficient performance, dissatisfaction with job, life and many mental pressures (Rastghar Khaled, 2006)

Rastghar Khaled (2004) identified the effects of social support as a resource for countering stress, study expectations arising from gender roles. Consequently, the research results concerning twojobbed families in Tehran-Iran explained the reasons for job-family conflicts. The study stated that women tend to enjoy social support and men tend to choose job support to counter stress and pressure. There are some issues, which have direct impact on work-life balance and have crucial roles in success of plans related to work and life. The importance of these issues is because of their high performance in encouragement and discouragement of staff in striking work-life balance (Perlow, 1995). Job consequence is associated with striking work-life balance. For instance, women having part-time jobs owing to childbirth have less financial advantages due to less work and employers cannot dedicate more advantages to these people due to high risks of investment on these people ( Griffin, 2000; Kirby \& Krone, 2002).

Therefore, each employee must dedicate certain number of hours to his/her job. Duration and method of dedicating time is dependent on them. Thus, an employee's record and attendance at his job increases his/her interest in his/her responsibility. According to this viewpoint individual participation and productivity is not sufficient but continuous attendance at job that is of paramount importance. Number of working hours causes regulation of individual performance to cope with different responsibilities. An individual must choose between roles of striking balance and occupational progress (Bailyn 1993, 1997).

Concerning work - life plans indiscrimination has been highlighted in choosing job options but most organizations have put more effort into facilitating working conditions of women and men have enjoyed fewer opportunities in this respect. (Strachan, 1998 \& Charlesworth, 1997. The fact that work-life policies have developed more for women is notable and it is the fourth relevant factor for employment of women. Current obstacles in the way of employing men arise from three main factors: first, structure and planning of working environment is not suitable for men and prevailing culture of these working environments do not allow employment of men. Second, working environments in which stress and competition is high prompts men to back away from work and life options. Third, the culture dominating the system of employers' families brings about loss of male access to worklife options. An instance could be given about families in which patriarchy dominates over matriarchy. (Bittman et al., 2004).

One crucial factor in resolving work-life issues is colleague support. According to this viewpoint, seizing upon opportunities present in working environment can cause dissatisfaction of staff. Enjoying special facilities can trigger positive or negative reactions from colleagues in working environment and thus reduce employees' belligerent attitudes towards each other (Kirby \& Krone, 2002). In the area of accounting, both private and state-owned firms have to deal with issues concerning work-life balance. While working, accountants are under significant amount of stress and pressure. Change in occupational standards, information technology, tax regulations and working conditions consumes significant amount of time of accountants. Competition at market requires enhancement of skills and abilities of accountants and the firms working with them. Still life is 
something more than work. Accountants like people in other areas provide some choices, which prompt them to give preference to some aspects of life other than work. The issue of work-life balance is paramount for both men and women. Yet women have attached the most importance to it. Current accountants and their employers make use of flex-time in order to facilitate work-life balance. How work-life balance affects job efficiency and staff well-being is a matter for debate. Frame and Hartog (2003) examined the effect of moralities on implementing policies regarding worklife balance in their working environment. The issue of work-life balance following studies carried out by Dloit \& Touch, audit firm Bigfor, which associated work-life balance with morality gained a lot of publicity. In their study, $91 \%$ of employees surveyed believed that if employees enjoyed a wellbalanced life, they would maintain morality. Sharon Allen- chairman of Deloit and Touch corporation presented the relationship between morality and work-life balance as follows:

If an individual puts all of his/her time and energy into his/her work, the consequence will be his/her dependency on his/her work in everything. This fact will boost his/her self-esteem. This issue complicates choice and when he/she is encountered with an ethical issue, that issue will influence his/her career success if he/she believes in it.

The relationship between work-life balances has been examined in a number of studies. Bloom and Reneen (2006) studied high competition in market products and administrative methods of AngloSaxon in creating increased productivity merely at the cost of work-life balance. They gathered data gathered from 732 manufacturing firms in the US, France, Germany and England and concluded that the results were relevant to optimum management. Therefore, successful companies are productive for their staff. Contrary to opinions of Bloom and Reneen (2006), White et al. (2003) identified conflicts in the above-mentioned methods and work-life balance. They analyzed data obtained from national surveys of British employees over the period 1992-2000. Work-life balance entailed a multitude of issues. This is a complicated issue since human being is complicated. Consequently issues related to work-life balance are complicated and there are no simple solutions for them. Recent studies on work-life balance address the following issues:

1. Spend time with family,

2. Rest and relaxation during leisure time,

3. Mental and physical well-being of family members,

4. Establish good relationship with others,

5. Cater to the needs of children and their education,

6. Satisfaction with things around the house (Karakas \& Lee, 2004).

The most complicated issue that professionals are faced with is how to split time between work and family. This issue has posed some challenges for all professions including accounting, commercial management, law, medicine and other professions. For instance, one of partners of Lauren Richlin law firm described job status and selflessness in his firm structure as intolerable. He stated that this issue was even more complicated with women (Muir, 2006). In the area of accounting, this issue can be a good reason for comparatively less participation on the part of women who have roles in accounting firms (AICPA, 2003). Looking for a various work-life balance might indicate low ratio of female participation in higher education of accounting (Feucht, 2009). Most people are afflicted by fatigue owing to much work and stress. While it is possible to shift work stress to some extra time, majority of men and women are in fact looking for reducing work time (Armour, 2003).

Flex-time is considered another solution to traditional work schedule. Employees might be in need of a flex-time to fulfill personal needs. An employee might pursue a different work schedule in order to win customer satisfaction. According to labor organization in the United States, statistics department $27.5 \%$ of the income of full-time employees worked flex-time, which enabled them to alter the beginning and end of their work time. 
Flex-time includes the following (research variables):

1. Flex-time: under flex-time employees are anticipated to be on duty during certain hours, whereas rest of the day is considered flex-time and they can select their work time. They might be obliged to work certain hours of the day or week or carry out a certain tasks.

2. Telecommuting: In this method, employees can have flexibility in the time and location of their work. By means of telecommuting, an individual can work somewhere other than his office. Telecommuting is also known as E-commuting, E-work and Telework.

3. Work at home options: for employees who work at home (WAH) or work from home (WFH) daily commute is replaced with Telecommuting links.

4. Part-time: employees have less work time in this option.

5. Job-sharing: in this option two employees having identical positions share their work time and responsibility.

6. Special summer or holiday work hours: in this option work time is different from normal work time.

\section{Research objectives}

This study pursues the following objectives:

1. Assessment of importance attached to work life balance from the viewpoint of accountants in choosing future jobs.

2. Examination of variables influential in striking work-life balance from the viewpoint of accountants.

\subsection{Research methodology}

In this study, the research method is descriptive survey and of the type "'applied". To attain objective of the research field survey has been conducted. In order to gather research data, two types of data; primary and secondary have been used. Secondary data collection includes records, documents, books, articles, search engines and relevant sites. Primary data collection includes questionnaire, interviews and population.

Casual class sampling method has been used to determine volume of the sample. Population of the research comprises active accountants and students on the verge of graduation with 220 questionnaires, which include 3 sections of general knowledge of participants (gender, education status and area of activity). In this survey, 6 questions were associated with importance of the status of accountants in work-life balance in Likert scale (from totally disagree to totally agree) and 6 questions are related to variables influencing in striking work-life balance in Likert scale (from totally disagree to totally agree). In addition, 205 questionnaires were the benchmark for conclusion. Statistical analysis has been carried out in two descriptive and inferential parts. In the descriptive part, general characteristics of the sample under study (gender, education status, interest in functioning in quadruple accounting areas) have been displayed through frequency tables.

In the inferential part, ANOVA test was employed to compare the two populations ( gender effect on 6 variables of importance of family balance and 6 variables influential in family balance). Friedman test was employed to rate research variables.

\section{Results, discussion and conclusion}

\section{1. descriptive statistics}

1. Descriptive statistics regarding participants 
Table 1

Descriptive statistics regarding participants

\begin{tabular}{cccc}
\hline Title & Explanation & Frequency & Frequency Percent \\
\hline Gender & Male & 98 & 47.8 \\
& Female & 107 & 52.2 \\
\hline \multirow{2}{*}{ Education Degree } & On the verge of graduation & 62 & 30.2 \\
& College & 59 & 28.8 \\
& Bachelor & 67 & 32.7 \\
& Master & 18 & 8.3 \\
\hline \multirow{3}{*}{ Activity Area } & Commerce & 75 & 36.6 \\
& Service & 39 & 19.0 \\
& Manufacturing & 35 & 17.1 \\
& State & 56 & 27.3 \\
\hline
\end{tabular}

\subsection{Inferential statistics}

Gender and six variables regarding importance of family balance from the viewpoint of accountants in choosing future jobs. The results obtained through ANOVA are displayed in table No.2.

Table 2

Test results of ANOVA, second section of the questionnaire

\begin{tabular}{|c|c|c|c|c|c|c|}
\hline Row & Question & Gender & No & Mean & $\mathrm{F}$ & Significance \\
\hline \multirow{3}{*}{1} & \multirow{3}{*}{$\begin{array}{l}\text { In choosing a job, I focus on how much WLB would be affected } \\
\text { by the job. }\end{array}$} & Male & 98 & 3.81 & \multirow{3}{*}{13.43} & \multirow{3}{*}{0.000} \\
\hline & & Female & 107 & 4.25 & & \\
\hline & & Total & 205 & 4.04 & & \\
\hline \multirow{3}{*}{2} & \multirow{3}{*}{ In choosing a job, the amount of flex-time is important to me. } & Male & 98 & 4.14 & \multirow{3}{*}{1.44} & \multirow{3}{*}{0.000} \\
\hline & & Female & 107 & 4.28 & & \\
\hline & & Total & 205 & 4.21 & & \\
\hline \multirow{3}{*}{3} & \multirow{3}{*}{ Access to flex-time is important in my long-term job satisfaction. } & Male & 98 & 3.94 & \multirow{3}{*}{10.51} & \multirow{3}{*}{0.001} \\
\hline & & Female & 107 & 4.30 & & \\
\hline & & Total & 205 & 4.13 & & \\
\hline \multirow{3}{*}{4} & \multirow{3}{*}{$\begin{array}{l}\text { Access to flex-time is important for employers to deal with } \\
\text { employees. }\end{array}$} & Male & 98 & 3.32 & \multirow{3}{*}{11.21} & \multirow{3}{*}{0.001} \\
\hline & & Female & 107 & 3.71 & & \\
\hline & & Total & 205 & 3.53 & & \\
\hline \multirow{3}{*}{5} & \multirow{3}{*}{ Good WLB yields better job performance. } & Male & 98 & 4.70 & \multirow{3}{*}{1.93} & \multirow{3}{*}{0.000} \\
\hline & & Female & 107 & 4.80 & & \\
\hline & & Total & 205 & 4.75 & & \\
\hline \multirow{3}{*}{6} & \multirow{3}{*}{ Good WLB yields decisions that are more ethical. } & Male & 98 & 4.37 & \multirow{3}{*}{2.687} & \multirow{3}{*}{0.000} \\
\hline & & Female & 107 & 4.57 & & \\
\hline & & Total & 205 & 4.47 & & \\
\hline
\end{tabular}

Test results suggest great significance in the balance between job and family from the viewpoint of experts (especially female accountants). In fact, accountants are interested in adopting flexible work schedules. They like to believe the impact of work-life balance on job performance and appropriate ethical decision making. Thus, the researcher concludes that managers must plan work schedules in a way so that no damage is done to work-life balance of employees especially employees having two jobs. This being done will lead to appropriate ethical decision making and increased job performance on the part of employees.

\subsection{The effects of $W L B$}

Results of the Friedman test are displayed in Table 3 and Table 4.

Table 3

Ranking medians based on significance

\begin{tabular}{lcccccc}
\hline Q & 1 & 2 & 3 & 4 & 5 & 6 \\
\hline Mean Rank & 4.72 & 4.14 & 3.71 & 3.54 & 3.30 & 2.11 \\
\hline
\end{tabular}


Table 4

Friedman test results

\begin{tabular}{cccc}
\hline No & Chi-Square & fd & Significance \\
\hline 205 & 327.491 & 5 & 0.000 \\
\hline
\end{tabular}

The results of Table 3 and Table 4 present the order of different variables in terms of their relative importance. Based on the results, people focus on how much WLB would be affected by the job when they intend to choose a job. In addition, flex-time is the second most important factor in our survey.

\subsection{Gender and 6 variables influential in striking work-life balance}

We now look at the influential variables in the second part of the survey.

Table 4

Results of ANOVA section two of the questionnaire

\begin{tabular}{|c|c|c|c|c|c|c|}
\hline Row & Variable & Gender & $\mathrm{N}$ & Mean & $\mathrm{F}$ & Significance \\
\hline \multirow{3}{*}{1} & \multirow{3}{*}{ Leisure time } & Male & 98 & 4.15 & \multirow{3}{*}{3.45} & \multirow{3}{*}{0.000} \\
\hline & & Female & 107 & 3.91 & & \\
\hline & & Total & 205 & 4.02 & & \\
\hline \multirow{3}{*}{2} & \multirow{3}{*}{ Part-time job } & Male & 98 & 3.59 & \multirow{3}{*}{2.03} & \multirow{3}{*}{0.001} \\
\hline & & Female & 107 & 3.81 & & \\
\hline & & Total & 205 & 3.70 & & \\
\hline \multirow{3}{*}{3} & \multirow{3}{*}{ Job sharing } & Male & 98 & 3.34 & \multirow{3}{*}{10.22} & \multirow{3}{*}{0.002} \\
\hline & & Female & 107 & 3.92 & & \\
\hline & & Total & 205 & 3.64 & & \\
\hline \multirow{3}{*}{4} & \multirow{3}{*}{ Work at home } & Male & 98 & 3.32 & \multirow{3}{*}{7.10} & \multirow{3}{*}{0.008} \\
\hline & & Female & 107 & 2.85 & & \\
\hline & & Total & 205 & 3.08 & & \\
\hline \multirow{3}{*}{5} & \multirow{3}{*}{ Holiday } & Male & 98 & 3.96 & \multirow{3}{*}{9.00} & \multirow{3}{*}{0.000} \\
\hline & & Female & 107 & 3.97 & & \\
\hline & & Total & 205 & 3.97 & & \\
\hline \multirow{3}{*}{6} & \multirow{3}{*}{$\begin{array}{c}\text { Modern } \\
\text { communications }\end{array}$} & Male & 98 & 3.77 & \multirow{3}{*}{0.429} & \multirow{3}{*}{0.000} \\
\hline & & Female & 107 & 3.87 & & \\
\hline & & Total & 205 & 3.82 & & \\
\hline
\end{tabular}

The results of Table 4 confirm that all six variables have statically significant effects on striking family balance. Therefore, optimum use of leisure time on the part of employees and labor division on the part of management create two equal types of occupational status. Management must divide responsibilities and the time needed to carry out tasks, appropriately. WFH, holiday and modern communications are other factors which managers and employees can make use of in line with striking work life balance.

\subsection{Studying identical significance of the six variables influential in striking work-life balance}

Freidman test results are displayed Table 5 and Table 6 and the results show that Leisure time is the most important factor followed by Part-time job and Job-sharing.

Table 6

Ranking medians based on significance

\begin{tabular}{lcccccc}
\hline Q & 1 & 2 & 3 & 4 & 5 & 6 \\
\hline Mean Rank & 3.95 & 3.94 & 3.71 & 3.43 & 3.39 & 2.58 \\
\hline
\end{tabular}

Table 7

Friedman test results

\begin{tabular}{cccc}
\hline No & Chi-Square & fd & Significance \\
\hline 205 & 327.491 & 5 & 0.000 \\
\hline
\end{tabular}




\section{References}

AICPA. (2003). AICPA, Summit: Career and Life in the Balance, AICPA Website:http://www.aicpa.org/Members/Div/career/wofi/2003_0512_summit.asp (May 12).

Anxo, D. (2007). Time allocation between work and family over the life-cycle: a comparative gender analysis of Italy, France, Sweden and the United States(No. 3193). IZA Discussion Papers.

Armour, S. (2003). More men seek better work-life balance, USA Today, Website:http://www.usatoday.com/money/workplace/2003-10-08-men_x.htm (October 8).

Azad Armaki, T. (2007). Sociology of Iranian families. First publication, Tehran: organization of studying and compiling books on humanities (SAMT).

Bailyn, L. (1993). Breaking the mold: Women, men and time in the new corporate world, Free Press, New York.

Bailyn, L. (1997). The impact of corporate culture on work-family integration, in Parasuraman, S., and Greenhaus, J. H. (eds), Integrating work and family: Challenges and choices for a changing world, Quorum Books, Westport, CT, pp. 209-19.

Bittman, M., Thompson, D., \& Hoffmann, S. (2004). Men's uptake of family-friendly employment provisions. Australia: Australian Government Department of Family and Community Services.

Bloom, N., \& Van Reenen, J. (2006). Management Practices, Work-L ife Balance, and Productivity: A Review of Some Recent Evidence. Oxford review of economic policy, 22(4), 457-482.

Charlesworth, S. (1997). Enterprise bargaining and women workers: the seven perils of flexibility. Labour \& Industry: A Journal of the Social and Economic Relations of Work, 8(2), 101-115.

Feucht, F. J., Kratchman, S. H., Smith, K. T., \& Smith, L. M. (2009). Changes in gender distribution among accounting academics. International Journal of Critical Accounting, 1(1), 110-122.

Frame, P., \& Hartog, M. (2003). From rhetoric to reality. Into the swamp of ethical practice: implementing work-life balance. Business Ethics: A European Review, 12(4), 358-368.

Griffin, M. G. (2000), Organisational values supportive of work and non-work integration (doctoral dissertation, California School of Professional Psychology), Dissertation Abstracts International, 61(03B), 1680.

Karakas, F., Lee, M. D., \& MacDermid, S. M. (2004). A qualitative investigation into the meaning of family well-being from the perspective of part-time professionals. Equal Opportunities International, 23(1/2), 57-77.

Kirby, E. L., \& Krone, K. J. (2002), The policy exists but you can't really use it, Communication and the structuration of work-family policies. Journal of Applied Communication Research, 30(1), 5072.

Kirby, E. L., \& Krone, K. J. (2002), The policy exists but you can't really use it, Communication and the structuration of work-family policies. Journal of Applied Communication Research, 30(1), 5072.

Paknahad Jabarouti, M. (2000). Gender and Sociology of Family. The book on social sciences p 48.

Perlow, L.A. (1995). Putting the work back into work/family. Group and Organization Management, 20(2), 227-39.

Rastghar khaled, A. (2006). Family, Job, Gender. Tehran, public relations of socio-cultural council of women.

Rastghar Khaled, A. (2004). The relationship between job and family, gender differences in enjoying social security. Female Research, 2, 55-75.

Strachan, G., \& Burgess, J. (1998), The "family friendly" workplace: Origins, meaning and application at Australian workplaces. International Journal of Manpower, 19(4), 250-65

Taghavi, N. (2000). Sociology of family. $4^{\text {th }}$ edition, Tehran, Payameh nour university

Tavassoli, G. (2008). Sociology of occupations. $9^{\text {th }}$ edition Tehran, organization of studying and compiling books on humanities (SAMT).

U.S. Department of Labor, Bureau of Labor Statistics. (2004). Bureau of Labor Statistics, Website: www.bls.gov. 